\title{
THE EFFECT OF ZNO ADDITION ON MICROSTRUCTURE, PHASE AND COLOR DEVELOPMENTS OF COPPER REDUCTION GLAZE
}

\author{
N. NayebPashaee ${ }^{1 *}$, A.M. Aarabi ${ }^{2}$, H. Sarpoolaky ${ }^{1}$, H. Vafaeenezhad ${ }^{1}$ \\ ${ }^{1}$ Iran University of Science and Technology, School of Metallurgy and \\ Materials Engineering, Tehran, Iran \\ ${ }^{2}$ Department of Nanomaterials \& Nanocoatings, Institute for Color Science and \\ Technology (ICST), Tehran, Iran.
}

Received 16.02.2015

Accepted 16.03.2015

\begin{abstract}
In this research, the effects of $\mathrm{Zn}$ on microstructure and color developments of the copper reduction glaze were investigated. Structural and colorimetric characteristics of the glaze surface are examined by X-ray diffraction, scanning electron microscope (SEM) equipped with electron dispersive spectroscopy (EDS) and Telespectrophotometery. Results indicate in samples consisted of more than $7 \%$ of zinc amount, crystalline structures containing Willemite and synthesized copper. XRD indicate that, $14 \mathrm{wt} \%$ of zinc oxide is enough to form Willemite. In all samples, duration of process was sufficient to form the metallic particles. SEM images confirm presence of copper nanosphere-laths of Willemite and surrounding glaze.

Keywords: Reduction glazes, brass alloy, uncontrolled atmospheres, Willemite

\section{Introduction}

Copper reduction glazes and glasses have a long history [1] extending from old Egypt as early as approximately $1500 \mathrm{BC}$ and Sung dynasty of China up to $13^{\text {th }}$ century to Yuan and Ming dynasties in $14^{\text {th }}$ and $17^{\text {th }}$ centuries, respectively. The copper reduction glazes were moved from China to Europe after uncovering the secret of porcelain making in $18^{\text {th }}$ century mainly in Germany and France [1]. Glazes with bright metallic shine have been interesting because of their high decorative value since $19^{\text {th }}$ century [2]. Iranian traditional glazed ceramics have been used for decorating mosques and buildings and they date back to $1250 \mathrm{BC}$. Iranian tile industry are mainly categorized into several types such as luster and luster-painted tiles (Zarrin Fam) or glazed tiles (Haft Rang) [3]. The most marvelous property of reduction glazes is their
\end{abstract}

\footnotetext{
* Corresponding author: N. NayebPashaee, nayebpashaee@iust.ac.ir
} 
attractive color which introduces some artistic aspects to them [4]. Red copper glazes are distinctive and have been highly prized in history. Iranian artists worked on reduction glazes in uncontrolled reduction creating many artistic works of attractive appearances.

It is well known that, the resultant glaze color is a combination of mutual effects of the colorant and the host, firing process as well as the amount and the nature of the colorant $[5,6]$. Pigments are extensively used in ceramic glazing technique to achieve decorative and colorful glazes [7-9]. The most important elements used as a source of color in glazes and enamel stains are transition elements which can form complexes in solution [4]. Oxides are often used as pigments because of their high stability in glazes [7]. As mentioned earlier, one of the most important pigments of transition (3d) elements used in glazes is copper [7,10] which provides a wide range of colors depending on glaze composition and firing atmosphere [4]. Copper has different oxidation states, so it can assigns different colors to glazes [5]. It produces a green or green-blue color when exposed to higher temperature or fire in an oxygen-rich atmosphere. However, a copper-containing glaze can produce a red color while being in reduction conditions. Copper in divalent form gives colors in sky blue or green, while being colorless as a single ion monovalent copper [10]. Beside acting as an active flux in the glaze, copper compounds also show special characteristics such as high solubility in all types of glazes and frits [4].

Two important categories of copper components widely used in reduction glazes are luster and red copper glazes. Luster is a reduced-pigmented thin layer glaze formed by a nanosized metal-glass composite made of copper and silver nanoparticles which are embedded in a glassy matrix $[2,11,12]$. The color and the transparency of the luster arise from its absorption and light scattering property [12]. A specific optical property of the luster is its capability to reflect light like a continuous metallic surface [2, 12]. It is worth noting that, light reflection in copper-rich lusters is similar to metallic copper [12].

Reduction luster was conventionally prepared in kiln using wood for providing the reducing atmosphere $[8,13]$. However, there is another way to achieve the reduction condition, i.e. using kiln with an over-rich fuel/air mixture or application of electrical heating kilns which use hydrocarbon gases for providing the reducing atmosphere [8]. In reduction firing, the kiln atmosphere has insufficient oxygen for a complete combustion. At elevated temperatures, carbon monoxide gas is produced which grabs loosely-bonded oxygen from other materials such as copper. This will change molecular form of the materials and cause color changes. Gas and electric kilns make it possible to control temperature, atmosphere and time during the reduction process much more precisely than conventional kilns though entail more safety considerations [8].

Another type of reduction glazes are copper red glazes, the colors of which are caused by dispersion of colloidal copper oxide in the glaze as a result of intense reduction firing atmosphere [14]. Wakamatsu et al. showed that in an intense reduction atmosphere followed by oxidizing atmosphere, the dominate forms of copper are $\mathrm{Cu}+$ and $\mathrm{Cu}_{2} \mathrm{O}[15,16]$. However, Kingery et al. reported that both metallic copper and $\mathrm{Cu}_{2} \mathrm{O}$ exist in the red copper glaze [14]. Tichane declared that it is only the metallic copper which makes the glaze red [1]. The most important point to produce the red copper glaze is the technique employed for providing a reduction condition [17]. 
Copper-zinc alloys (brasses) are probably the most widely used copper-base alloys [18]. Meanwhile, brasses are also the most important copper alloys because of their color features. The color of brasses varies from a light, bright "yellowish" to a moderately dark "reddish" color, depending on the ratio of alloying elements. Generally speaking, the higher copper content makes the appearance darker and more reddish [18].

Taking into account the interesting aspects of copper reduction glazes, the purpose of the current study was to investigate the effect of $\mathrm{ZnO}$ addition on microstructure, phase and color developments of historical copper reduction glaze.

\section{Experimental}

The glaze chosen for this research was transparent frit, while $7-8 \mathrm{wt} \%$ of copper carbonate was used as the source of copper. For investigating the effect of additives, $0-20 \mathrm{wt} \% \mathrm{Zn}$ was added to each batch. The obtained powder was mixed with water and then applied over a biscuit tile $(3 \times 3 \mathrm{~cm})$. The tile samples were let to be dried up before firing. Afterwards, tile samples were fired in a typical chamber kiln $(100 \times$ $100 \mathrm{~cm}$ ) at about $1000^{\circ} \mathrm{C}$ in an oxidation atmosphere. Samples were later exposed to uncontrolled reduction atmosphere by burning wood.

In uncontrolled reduction condition, samples were heated up to $900^{\circ} \mathrm{C}$ and some pieces of wood were used for creating the reduction atmosphere after turning off the kiln. The glaze samples obtained in the presence of $0,7,14$ and $20 \mathrm{wt} . \%$ zinc oxide were coded as GCZ0, GCZ7, GCZ14 and GCZ20, respectively.

Phase analysis was performed by X-ray diffraction apparatus operating at $40 \mathrm{kV}$ and $30 \mathrm{~mA}$ using $\mathrm{Cu} \mathrm{K} \alpha$ radiation $\left(\mathrm{k}=1.5418 \mathrm{~A}^{\circ}\right)$ and $\mathrm{Ni}$ filter. A scanning electron microscope (SEM) equipped with electron dispersive spectroscopy (EDS) analyzer was utilized for examination and characterization of layer thickness, surface morphology, surface particles as well as analysis of the particles formed.

Reflectance spectra and colorimetric characteristics of different glaze samples were assessed by a Tele-spectrophotometer instrument (CS2000 Minolta, Japan).

\section{Results and Discussion}

\section{Structural Studies}

X-ray diffraction patterns of the samples obtained by surface reduction of glazes are shown in Figure 1. As it can be seen, one considerable consequence of the surface reduction of copper- and zinc- containing glazes is the formation of metallic structures which create a metallic appearance. Although the glaze in all samples mainly consisted of an amorphous structure, the amount of reduced metallic copper detected in the XRD patterns was insignificant. The main crystalline phases in glaze samples with relatively high amount of zinc were Willemite as well as synthesized metallic copper and in the others, i.e. ones with 0 to $7 \mathrm{wt} . \%$ zinc oxide just have synthesized metallic copper in their structure. In another words, in contrast to GCZ0 and GCZ7, Willemite was detected in GCZ14 and GCZ20 samples. It means that the ZnO supersaturation was not occurred in GCZ7 sample for Willemite phase formation. This can be attributed to insufficient amount of zinc oxide in the starting batch. However, the crystalline structure and the intensity of diffraction patterns are significantly affected by the zinc content. It is found that the initial structure of these samples is zinc silicate (JCPDS No. 00-037-1485, Rhombohedra, space group: R-3). 
Shen et al. [19] demonstrated that the glaze can be decomposed to ( $\mathrm{Zn}, \mathrm{Ti}, \mathrm{Ca}$ )rich and $(\mathrm{Si}, \mathrm{Al}, \mathrm{K}, \mathrm{Na})$-rich regions, from which Willemite is crystallized and amorphous droplets are formed, respectively. Application of an intense reduction condition increases the possibility of zinc-copper alloy formation. On the other hand, zinc shows a greater tendency to react with silicate component of the glaze in order to form crystalline Willemite [20]. Moreover, it seems that the applied reduction conditions were capable of forming copper metallic particles.

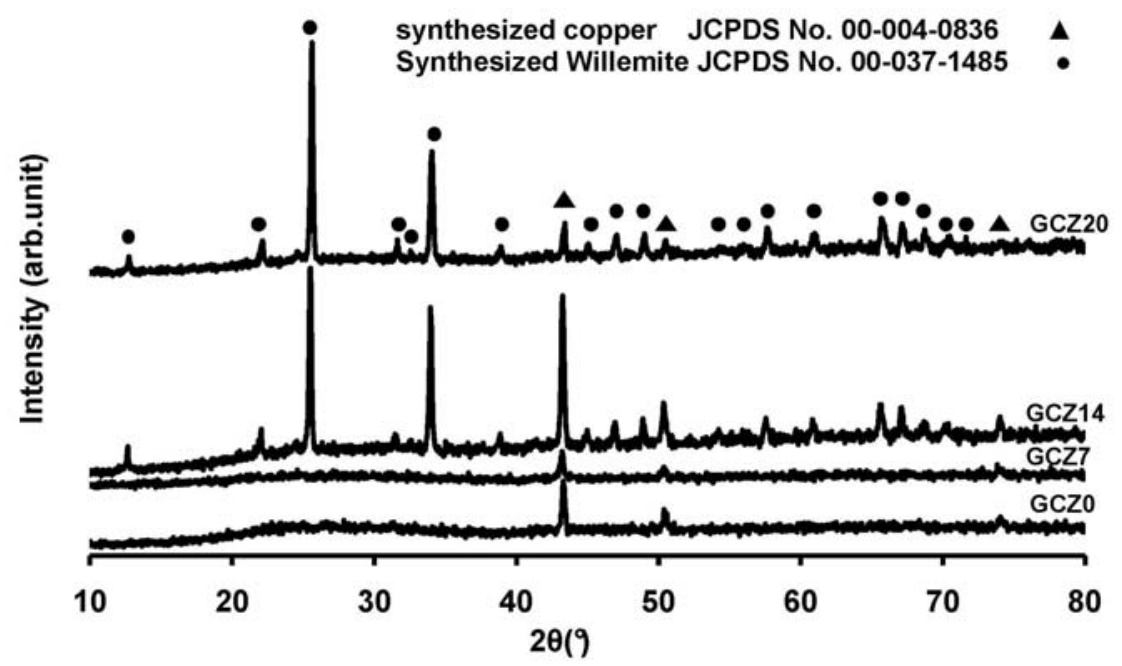

Fig. 1. X-ray diffraction patterns of GCZ0, GCZ7, GCZ14 and GCZ20 samples.

As can be seen in Figure 1, main XRD peaks which appeared in GCZ0 sample belong to a synthesized copper structure (JCPDS No. 00-004-0836, cubic, Space group: Fm3m). In GCZ7, introducing the zinc to glaze leads to formation of a greater amount of synthesized metallic copper. It is expected that, zinc and copper alloys are readily formed because of a wide range of solid solution present in $\mathrm{Cu}-\mathrm{Zn}$ phase diagram [21]. Nevertheless, as can be observed from the X-ray patterns of GCZ14 and GCZ20 samples, there is not a strong tendency between copper and zinc to form the alloy and competition of the abovementioned mechanisms leads to formation of Willemitemetallic copper composite.

\section{Morphological Studies}

As illustrated in Figure 1, a composite of Willemite and metallic copper is formed by increasing zinc content of the glaze. Morphological studies on different glazes consisting of various amounts of zinc are necessary to characterize the Willemite-metallic copper composite. SEM images of GCZ0, GCZ7, GCZ14 and GCZ20 samples are depicted in Figure 2. Spherical nanoparticles obtained during reduction process of GCZ0 and GCZ7 samples may be attributed to the synthesized metallic copper (Figure 2a). EDS spectra of GCZ7, GCZ14 and GCZ20 samples are shown in Figures $2 \mathrm{c}, 2 \mathrm{e}$ and $2 \mathrm{~g}$, respectively. Table 1 also summarizes the atomic percentage of the elements detected by EDS analysis. High amount of copper in 
addition to the low amount of zinc detected in nanospheres in GCZ7 sample (Figure $2 b$ point 1 , Figure $2 \mathrm{c}$ and Table 1) confirms the efficient reduction of $\mathrm{CuO}$ to $\mathrm{Cu}$. However, the introduction of Zn to GCZ14 and GCZ20 samples leads to formation of lath-like particles with morphologies almost similar to Willemite. EDS analysis of these particles reveals the formation of Willemite (Figures $2 \mathrm{e}$ and $2 \mathrm{~g}$, in points 2 and 3, respectively), while other observations indicate that, the same oriented Willemite is formed within the glaze matrix [22]. However, the authors have addressed the formation of acicular morphologies in the matrix and this change in the crystal morphology can be inferred to the uncontrolled reduction process. Furthermore, the appearance of a few spherical particles in GCZ14 can be assigned to the metallic copper, which is in good agreement with performed structural studies. It should be added that, the decreased metallic copper content in GCZ20 might be due to the partial solution of copper in Willemite structure [4]. A comparison between the shape and the size of the laths in Figures $2 \mathrm{~d}$ and $2 \mathrm{f}$ indicates that the width of the laths has been doubled (from 3 to $6 \mu \mathrm{m}$ ) in GCZ20 sample. Additional larger particles can be obtained by enhancement of the copper dissolution in Willemite structure which in turn reduces the amount of spherical metallic copper particles.

Table 1. EDS analysis of GCZ7 (1), GCZ14 (2) and GCZ20 samples

\begin{tabular}{|c|c|c|c|c|c|c|c|c|c|}
\hline \%at & Silicon & Aluminum & Potassium & Calcium & Zinc & Copper & Sulfur & Oxygen & Gold \\
\hline 1 & 21.60 & 5.12 & 1.67 & 1.40 & 1.29 & 15.99 & 7.76 & 41.24 & 3.93 \\
\hline 2 & 19.06 & 1.41 & 0.58 & - & 31.00 & 0.72 & - & 43.82 & 3.48 \\
\hline 3 & 17.97 & 1.50 & 0.45 & - & 28.77 & 0.44 & - & 47.67 & 3.19 \\
\hline
\end{tabular}

\section{Color Properties}

The formation mechanism and different aspects of copper red glaze through reduction process have been widely reported in the literature $[4,7,10]$. Also, high dependency of the reflected light to the incident angle was shown in lustrous and metallic surfaces. This phenomenon occurs due to various arrangements of the metallic particles on surface of the glazes [4]. Reillon et al. [23] argued that, chemical composition of the glaze is not the only parameter for explanation of the optical properties of luster. Regarding this mater, optical characterization and reflection spectra demonstrated that, both the concentration and the size of metallic nanoparticles are important to explain colored metallic shine of the luster. It can be deduced that, there is a correlation between chemical composition, colorimetric characteristics and luster metallic properties of the glaze surface.

Metallic surfaces are usually characterized by Gonio-spectrophotometer which extracts the variations of reflectance spectra with incident angles. However, Goniospectrophotometer cannot report the exact results from outer surface of the glazes. The main reason is the great roughness of the glazes which enhances their light scattering. Because of the narrow size of spots in Tele-spectrophotometer, colorimetric characterization of the glaze metallic surfaces is expected to be more accurate.

Figure 3 presents macro image of GCZ0 sample during the colorimetric process. In this Figure, the location of spectrophotometer is specified by a white arrow. Reflectance spectra of GCZ0, GCZ7, GCZ14 and GCZ20 samples at $15^{\circ}$ and $45^{\circ}$ are shown in Figures $4 a$ and $4 b$, respectively. 


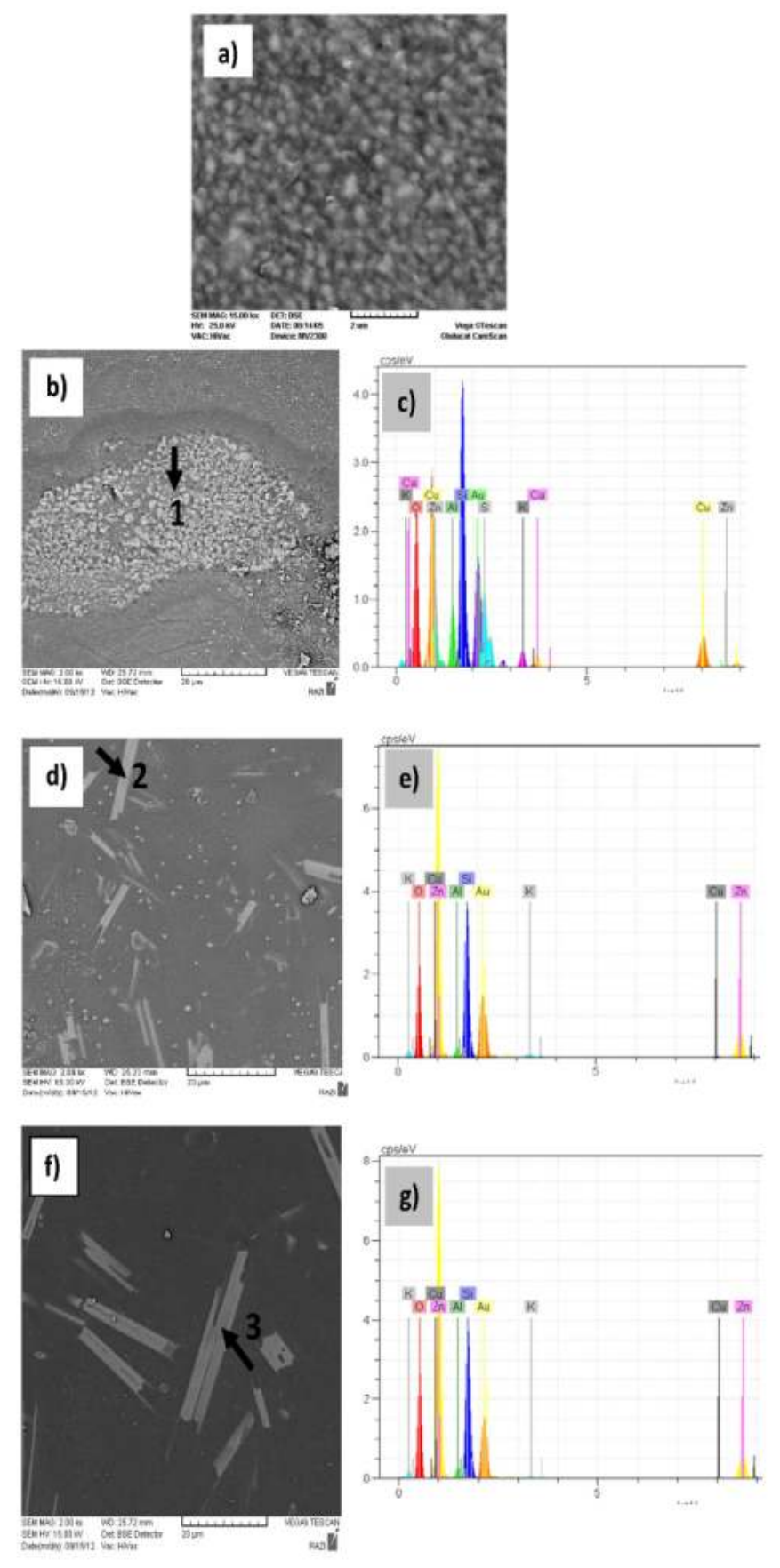


Fig. 2. SEM images and EDS analysis of: (a) GCZ0, (b,c) GCZ7, (d,e) GCZ14 and (f,g) GCZ20 samples. (Arrows show the spot position in EDS analyzer) (The numbers denote the location of EDS analyzer).

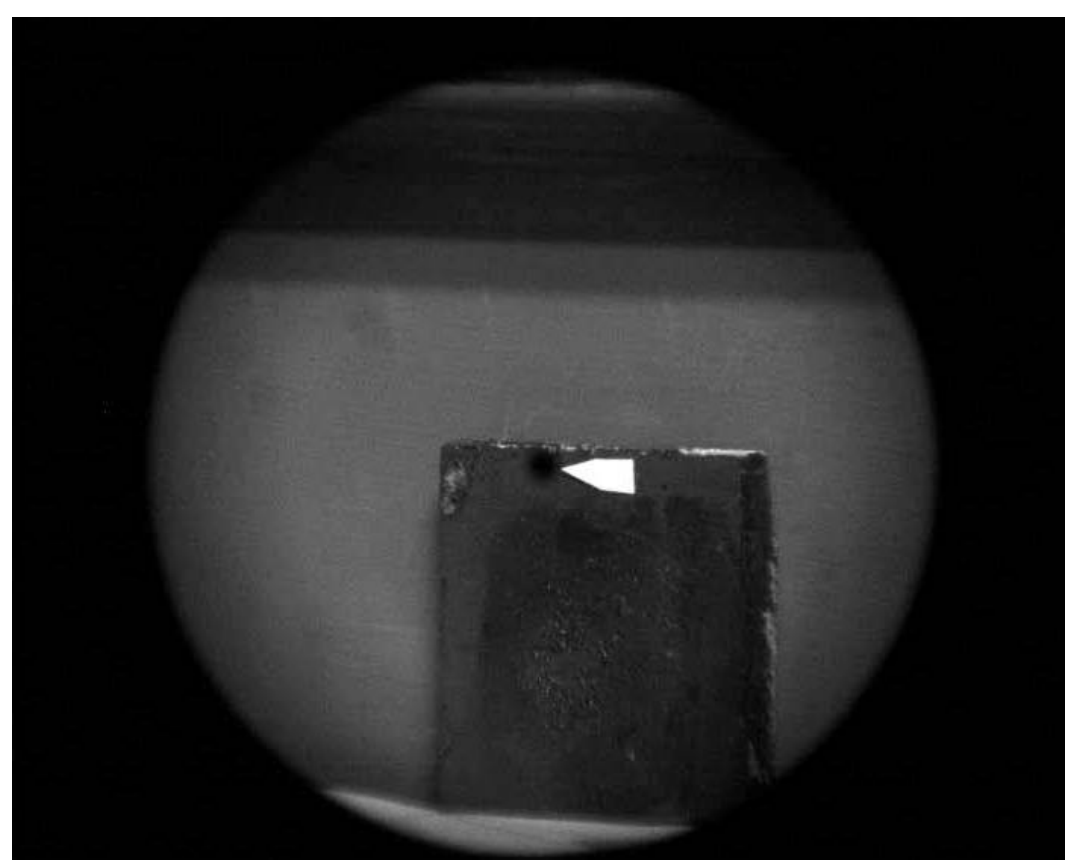

Fig. 3. Macro image of GCZ0 sample during colorimetric process (the location of spectrophotometer has been shown by a white zone).

All the spectra included a distinct reflectance near visible wavelengths which shows a vigorous tone of red for all samples. However, reflectance percentages vary with respect to the amount of zinc in the glaze compound. The composition of the glaze also affects the reflectance spectra located in the visible range. For example, GCZ7 shows another reflectance enhancement region as a wide peak between $380-580 \mathrm{~nm}$. In summary, it can be supposed that the feature of any spectrum is affected by the zinc content of the glaze.

Table 2. Colorimetric characteristics of GCZ0, GCZ7, GCZ14 and GCZ20 samples

\begin{tabular}{|c|c|c|c|c|c|c|}
\hline $\begin{array}{c}\text { Code of } \\
\text { samples }\end{array}$ & $\begin{array}{c}\text { The angle } \\
\text { of light } \\
\text { incident }\end{array}$ & $\mathrm{a}^{*}$ & $\mathrm{~b}^{*}$ & $\mathrm{~L}^{*}$ & $\mathrm{C} *$ & $\mathrm{~h}$ \\
\hline GCZ0 & 15 & 19.38 & 11.88 & 41.77 & 22.73 & 31.5 \\
\hline GCZ0 & 45 & 17.25 & 9.38 & 40.36 & 19.63 & 28.53 \\
\hline GCZ7 & 15 & 12.06 & 4.3 & 49.07 & 12.81 & 19.62 \\
\hline GCZ7 & 45 & 7.31 & 0.91 & 49.14 & 7.37 & 7.06 \\
\hline GCZ14 & 15 & 10.29 & 2.77 & 38.79 & 10.66 & 15.07 \\
\hline GCZ14 & 45 & 10.09 & 2.06 & 36.7 & 10.3 & 11.54 \\
\hline GCZ20 & 15 & 11.7 & 6.96 & 39.75 & 13.61 & 30.74 \\
\hline
\end{tabular}




\begin{tabular}{|l|l|l|l|l|l|l|}
\hline GCZ20 & 45 & 10.96 & 5.56 & 34.11 & 12.29 & 26.91 \\
\hline
\end{tabular}

The best method to characterize the colorimetric properties of a surface is determination of chroma $\left(\mathrm{C}^{*}\right)$ and hue angle (h) parameters which are defined by the following equations [23]:

$$
\begin{aligned}
& \mathrm{C}^{*}=\left\{\left(\mathrm{a}^{*}\right)^{2}+\left(\mathrm{b}^{*}\right)^{2}\right\}^{1 / 2} \\
& \mathrm{~h}=\tan ^{-1}\left(\mathrm{~b}^{*} / \mathrm{a}^{*}\right)
\end{aligned}
$$

Where $\mathrm{a}^{*}$ and $\mathrm{b}^{*}$ are color-opponent dimensions determined by color spectrophotometry. The colorimetric characteristics of GCZ0, GCZ7, GCZ14 and GCZ20 samples in different angles of incident light are listed in Table 2. The most noticeable observation of colorimetric data is the distinct decrease of additional colorimetric parameters such as $\mathrm{a}^{*}, \mathrm{~b}^{*}$ and $\mathrm{C}^{*}$ with the increase of zinc content. For example, color saturation which is determined by $\mathrm{C}^{*}$ value is altered from 22.73 in GCZ0 sample to 13.61 in GCZ20 sample by higher amount of zinc oxide in the glaze cimposition. However, the lightness value of all samples remains unchanged. Moreover, there is no significant change in $\mathrm{h}$ value while the zinc content is changed to a large extent. Reflectance spectra and colorimetric properties of various samples indicate that, zinc content of the glaze has a considerable effect on color properties. The decrease in $\mathrm{C}^{*}$ from GCZ0 to GCZ20 samples uncovers a decrease in the color saturation. This can be attributed to the formation of Willemite crystals and partial dissolution of copper in zinc silicate structure [4]. As illustrated by structural and morphological studies of the glaze surface, there is a close competition between formation of Willemite, metallic copper and copper-zinc alloys, which is further confirmed by the great change of colorimetric data. In the absence of zinc, hue values are fixed at about 30. In GCZ7 sample, $\mathrm{h}$ value is changed to 19 with respect to the introduction of zinc oxide into the composition of the glaze. The color change in this sample might be related to the formation of a few amounts of copper-zinc alloys. The introduction of a higher amount of zinc in the glaze leads to formation of Willemite in GCZ14 sample. Consistent with the formation of a new structure, the descending trend of $h$ value is terminated and $h$ value returns to 30 in GCZ20 sample. These changes can be simply attributed to the structure of Willemite due to its high ability for copper dissolution. In abovementioned competition, the formation of zinc silicate compound and simultaneous introduction of copper into Willemite will decrease the chance of copper-zinc alloy formation. Although the obtained hue of the sample is totally dependent on zinc oxide, the variation of chroma (color saturation) reveals a lower sensitivity to composition of the glazes. This is probably because that the crystal type is more effective on hue than the color saturation. It seems that the latter depends on quality and the number of crystals on the surface of the glazes which is not much affected by the amount of zinc oxide (0$20 \mathrm{wt} \%$ ). The variation of $\mathrm{C}^{*}$ and $\mathrm{h}$ values of GCZ020 sample versus the angle of incident light confirms the metallic properties of the glaze surface. This observation is in good agreement with the change of colorimetric data obtained in different incident angles of light (Table 2). As can be seen in Figure 4, reflectance spectra are also in good agreement with the colorimetric data. 

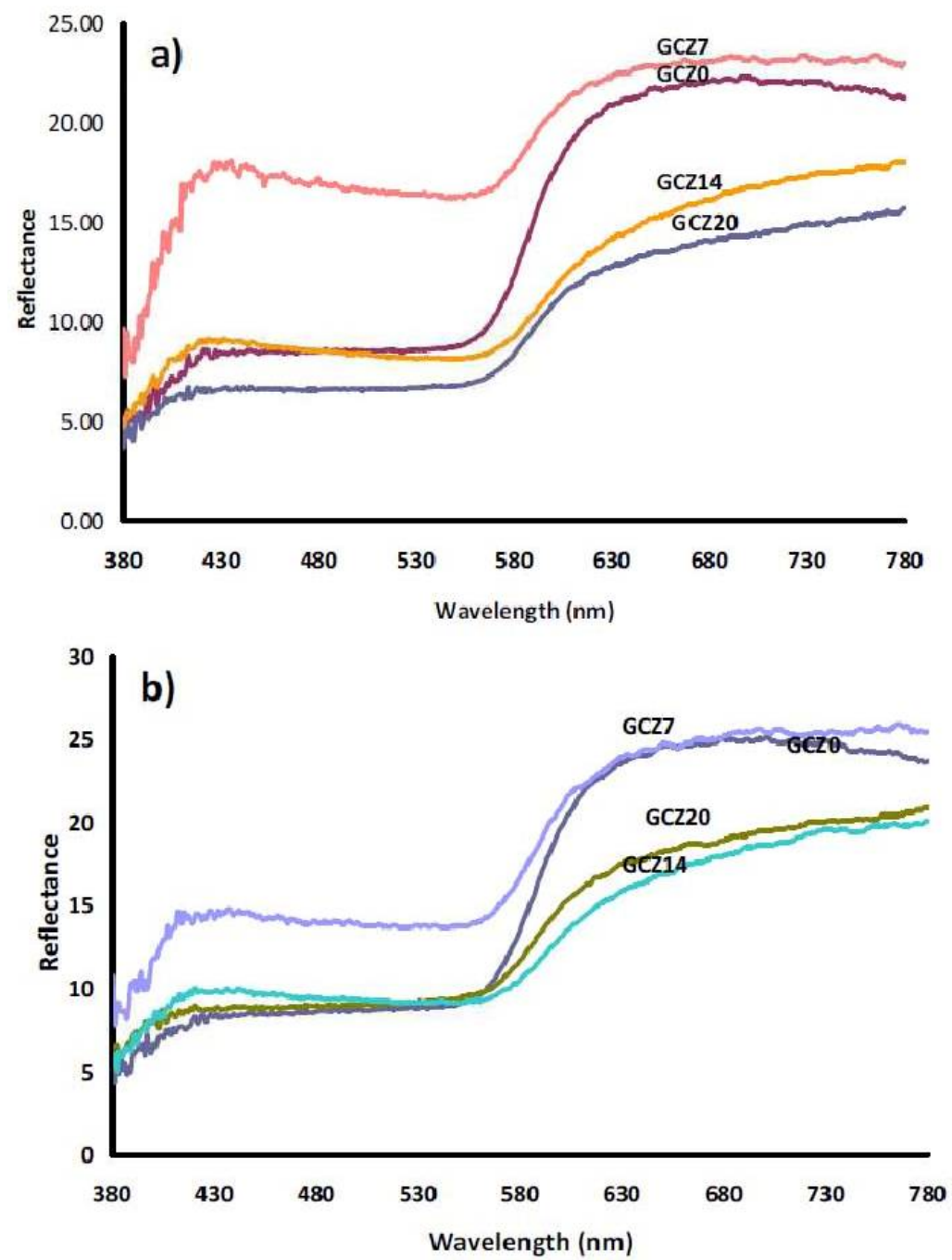

Fig. 4. Reflectance spectra of GCZ0, GCZ7, GCZ14, GCZ20 samples. The angle of light incident was fixed at: (a) $15^{\circ}$ and (b) $45^{\circ}$.

\section{Conclusion}

In this research, the effect of zinc oxide addition on microstructure, phase and color developments of historical copper reduction glaze was investigated. The following conclusions can be highlighted in this regard:

1. Glazed samples with relatively higher amount of zinc oxide consisted of crystalline structures containing Willemite and synthesized copper. The formation of composite was also noticed on the surface of the glazes. However, 
samples with zinc up to $7 \mathrm{wt} . \%$ zinc oxide just have metallic copper in their atomic structure.

2. Willemite was detected in the presence of 14 and $20 \mathrm{wt} \%$ of zinc oxide with the same amounts of copper oxide while there was no evidence of such phase in 0 and $7 \mathrm{wt} \%$ containing samples.

3. The reduction process was able to form metallic particles in all the samples. However, either decreasing or increasing of the copper content depend on some other parameters such as zinc oxide content, dissolution of copper in Willemite, etc.

4. Morphological studies revealed that copper nanospheres are formed on the surface of the glazed sample. This morphology was gradually changed to a lath-like Willemite by further introduction of zinc oxide. Copper-Willemite composite was also observed.

5. Colorimetric characteristics and reflectance spectra demonstrates the strong effect of zinc oxide content of the glaze on color saturation $\left(\mathrm{C}^{*}\right)$ and hue $(\mathrm{h})$ in the glazed samples. Color saturation was significantly decreased from 22 to 12 by higher amounts of zinc oxide in the glaze composition. However, the obtained hue of the sample is totally dependent on zinc oxide, the variation of chroma (color saturation) reveals a lower sensitivity to composition of the glazes. Lightness of all samples was almost the same. The change of $\mathrm{C}^{*}$ and $\mathrm{h}$ with the incident angle of light indicate metallic properties at the outer surface of the glazes. Reflectance spectra were also in good agreement with the colorimetric data.

\section{References}

[1] R.Tichaine, "Copper red glazes", 2nd edition, Krause Pub. (1998).

[2] J.J. Reinosa, J.J. Romero, P. Jaquotot, M.A. Bengochea, J.F. Fernández: "Copper based hydrophobic ceramic nanocoating “, J. Eur. Ceram. Soc. 32(2012) 277-282.

[3] M. T. Doménech-Carbó, A. Doménech-Carbó, D. J. Yusá-Marco, H. Ahmadi, "Characterization of Iranian Moarraque glazes by light microscopy, SEM-EDX and voltammetry of microparticles", J.Cult. Herit. 9 (2008) 50-54.

[4] B. Karasu, S. Turan, "Effects of cobalt, copper, manganese and titanium oxide additions on the microstructures of zinc containing soft porcelain glazes", J. Eur. Ceram. Soc., 22(2002) 1447-1455.

[5] A. Silvestri, S. Tonietto, F. D'Acapito, G. Molin, J.Cult. Herit. "The role of copper on colour of palaeo-Christian glass mosaic tesserae: An XAS study" 13 (2012) 137144.

[6] O. Bobin, M.S., C. Ney, M. Rammah, B. Pannequin, E. Cilia Platamone, A. Daoulatli, R. P. Gayraud, "The role of copper and silver in the coloration of metallic luster decorations (Tunisia, 9th century; Mesopotamia, 10th century; Sicily, 16th century) “, Color Res. Appl., 28 (2003) 352-359.

[7] E. Ozel, S. Turan, "Production and characterisation of iron-chromium pigments and their interactions with transparent glazes", J. Eur. Ceram. Soc., 23(2003) 20972104.

[8] J. P. Malins, K. H. Tonge, "Reduction processes in the formation of lustre glazed ceramics", Thermochim. Acta, 395(1999) 340-341. 
[9] M. Llusar, J.A. Badenes, A. Garcı'a, C. Gargori, R. Galindo, G. Monro's, "Solid solutions of mixed metal Mn3 xMgxFe4(PO4)6 orthophosphates: Colouring performance within a double-firing ceramic glaze", Ceram. Int. 37(2011) 493-504.

[10] F. Farges, M.P. Etcheverry, A. Scheidegger, D. Grolimund, "Speciation and weathering of copper in "copper red ruby" medieval flashed glasses from the Tours cathedral (XIII century)”, Appl. Geochem., 21(2006) 1715-1731.

[11] J. Roqu'e, J. Molera, P. Sciau, E. Pantos, M. Vendrell-Saz, "Copper and silver nanocrystals in lustre lead glazes: Development and optical properties", J. Eur. Ceram. Soc., 26 (2006) 3813-3824.

[12] T. Pradell, J. Molera, A. D. Smith, A. Climent-Font, M. S. Tite, "Technology of Islamic luster", J.Cult. Herit., 9 (2008) 123-128.

[13] J. Malins, K. H. Tonge, "Reduction lustre glazes and pigments", Br. Ceram. Trans., 92(1993) 83-88.

[14] W.D. Kingery, P. B. Vandiver, "Ceramic masterpieces”, New York: Free Press,(1986).

[15] M. Wakamatsu, N. Takeuchi, "Effect of heating and cooling atmospheres on colors of glaze and glass containing copper", J. Non-crystalline Solids. 80(1986) 412-421.

[16] M. Wakamatsu , N. Takeuchi , H. Nagai, "Chemical states of copper and tin in copper glazes fired under various atmospheres", J. Ceram. Association. Japan, 94(1989) 16-19.

[17] J. Britt, "High-fire glazes", 1st Pub, lark books, (2007).

[18] J.R. Davis, "Copper and copper alloys”, ASM international,( 2001).

[19] C. Sun, C. Kuan, F.J. Kao, Y.M. Wang, J.C. Chen, C.C. Chang, P. Shen, "On the nucleation, growth and impingement of plate-like $\alpha-\mathrm{Zn} 2 \mathrm{SiO} 4$ spherulites in glaze layer: a confocal and electron microscopic study", Mater. Sci. Eng. A 379(2004) 327-333.

[20] B. EftekhariYekta, P. Alizadeh, L. Rezazadeh, "Synthesis of glass-ceramic glazes in the $\mathrm{ZnO}-\mathrm{Al} 2 \mathrm{O} 3-\mathrm{SiO} 2-\mathrm{ZrO} 2$ system”, J. Eur. Ceram. Soc., 27 (2007)23112315 .

[21] T. B. Massalski, "Binary Alloy Phase Diagrams", 2nd ed., (1990).

[22] K. M. Knowles, F. S. H. B. Freeman, "Microscopy and microanalysis of crystalline glazes", J Microsc., 245(2004)257-270.

[23] V.Reillon, S. Berthier: "Modeling of the optical and colorimetric properties of lustred ceramics", Appl. Phys. A, 83 (2006) 257-265.

[24] R.McDonald, "Colour physics for industry", Society of Dyers and Colourists, (1997). 